\title{
Erratum to: Polymorphisms in GCKR, SLC17A1 and SLC22A12 were associated with phenotype gout in Han Chinese males: a case-control study
}

Zhao-Wei Zhou ${ }^{1,2}$, Ling-Ling Cui ${ }^{1,2}$, Lin Han ${ }^{1,2}$, Can Wang ${ }^{1,2}$, Zhi-Jian Song ${ }^{3}$, Jia-Wei Shen ${ }^{3}$, Zhi-Qiang Li ${ }^{3}$, Jian-Hua Chen ${ }^{3}$, Zu-Jia Wen ${ }^{3}$, Xiao-Min Wang ${ }^{1,2}$, Yong-Yong Shi ${ }^{3^{*}}$ and Chang-Gui Li $i^{1,2^{*}}$

\section{Erratum}

Unfortunately the original version of this article [1] contained a mistake. It came to the authors' attention that the corresponding authors of the article were not listed correctly, an error which arose during production. Both Yong-Yong Shi (yongyongshi@gmail.com) and Chang-Gui Li (licgqd@163.com) should have been listed as joint corresponding authors.

The full author list should read:

Zhao-Wei Zhou ${ }^{1,2}$, Ling-Ling Cui ${ }^{1,2}$, Lin $\mathrm{Han}^{1,2}$, Can Wang ${ }^{1,2}$, Zhi-Jian Song ${ }^{3}$, Jia-Wei Shen ${ }^{3}$, Zhi-Qiang $\mathrm{Li}^{3}$, Jian-Hua Chen ${ }^{3}, \mathrm{Zu}-J i a \mathrm{Wen}^{3}$, Xiao-Min Wang ${ }^{1,2}$, YongYong $\mathrm{Shi}^{3^{3 \prime}}$ and Chang-Gui $\mathrm{Li}^{1,2^{n}}$

"Corresponding authors: Chang-Gui Li licgqd@163.com and Yong-Yong Shi yongyongshi@gmail.com.

\section{Author details \\ 'Shandong Gout Clinical Medical Center, The Affiliated Hospital of Qingdao University, 16 Jiangsu Road, Qingdao 266003, China. ${ }^{2}$ Shandong Provincial Key Laboratory of Metabolic Disease, The Affiliated Hospital of Qingdao University, 16 Jiangsu Road, Qingdao 266003, China. ${ }^{3}$ Bio-X Institutes, Key Laboratory for the Genetics of Developmental and Neuropsychiatric Disorders (Ministry of Education), Shanghai Jiao Tong University, Shanghai 200030, China.}

Published online: 28 October 2015

\section{Reference}

1. Zhou ZW et al. Polymorphisms in GCKR, SLC17A1 and SLC22A12 were associated with phenotype gout in Han Chinese males: a case-control study. BMC Med Genet. 2015;16:66.

\footnotetext{
* Correspondence: yongyongshi@gmail.com; licgqd@163.com ${ }^{3}$ Bio-X Institutes, Key Laboratory for the Genetics of Developmental and Neuropsychiatric Disorders (Ministry of Education), Shanghai Jiao Tong University, Shanghai 200030, China

'Shandong Gout Clinical Medical Center, The Affiliated Hospital of Qingdao University, 16 Jiangsu Road, Qingdao 266003, China

Full list of author information is available at the end of the article

Submit your next manuscript to BioMed Central and take full advantage of:

- Convenient online submission

- Thorough peer review

- No space constraints or color figure charges

- Immediate publication on acceptance

- Inclusion in PubMed, CAS, Scopus and Google Scholar

- Research which is freely available for redistribution 